OPEN ACCESS

Edited by:

Anders Hansen,

University of Leicester,

United Kingdom

Reviewed by:

Matthew Cotton

University of York, United Kingdom

Emma Frances Bloomfield,

University of Nevada, Las Vegas,

United States

*Correspondence:

Sibo Chen

sibo.chen@ryerson.ca

Specialty section: This article was submitted to

Science and Environmental

Communication,

a section of the journal

Frontiers in Communication

Received: 23 July 2020 Accepted: 30 November 2020 Published: 17 December 2020

Citation:

Chen S (2020) A Bridge to Where? Tracing the Bridge Fuel Metaphor in the Canadian Media Sphere.

Front. Commun. 5:586711 doi: $10.3389 /$ fcomm.2020.586711

\section{A Bridge to Where? Tracing the Bridge Fuel Metaphor in the Canadian Media Sphere}

\author{
Sibo Chen* \\ School of Professional Communication, Ryerson University, Toronto, ON, Canada
}

This paper examines how Canadian media have discussed the role of natural gas in climate change mitigation from 2016 to 2019. It also explicates different stakeholders' varying stances on the environmental impacts of North America's ongoing "shale gas boom," as manifested in their conflicting attitudes toward designating unconventional gas as a bridge to a low-carbon future. The data in question consist of 99 articles published by Canadian media sources, all of which included explicit references to either "bridge fuel" or "transition fuel." Through a qualitative thematic analysis, I found that more than half of the articles adopted the conventional definition of bridge fuel. Meanwhile, there are three less common, yet noteworthy interpretations arising out of the rest of the articles, which conflict with each other in terms of their views on the relationship between unconventional gas and greenhouse gas emissions reduction. Overall, the fact that bridge fuel references only appeared in a fraction of Canadian environmental and energy news reports during the target period suggests the issue's peripheral status in the Canadian media sphere. Given this situation, the paper ends by calling for more knowledge mobilization efforts to raise public awareness of the controversial factors underlying expanding unconventional gas production and consumption.

Keywords: bridge fuel, transitional fuel, shale gas, energy transition, energy discourse

\section{INTRODUCTION}

In both the United States and Canada, the "shale gas boom" since the late 2000's has provoked concerted government and industry propaganda promoting the construction of new gas infrastructure. A key metaphorical expression emerging from such promotional efforts is the proposal of natural gas as a "bridge fuel" that facilitates the transition to low-carbon and eventually renewable energy systems (Healey and Jaccard, 2016; Ogden et al., 2018). Take the International Energy Agency (IEA) as an example. In June 2011, the organization published a widely circulated special report titled "Are We Entering a Golden Age of Gas?" (The International Energy Agency, 2011), claiming that if following best practices, expanding gas production and consumption could "lead to lower emissions of greenhouse gases and local pollutants, $[\ldots]$ and help to diversify energy supply and improve energy security" (p. 7).

This optimistic outlook was immediately picked up by fossil fuel proponents from both government and industry, who began to frequently frame the extraction of shale gas as a climate solution. In Canada's westernmost province British Columbia (BC), for instance, the provincial government has justified its pursuit of establishing an export-oriented liquefied natural gas (LNG) industry by consistently referring shale gas produced via hydraulic fracturing as the world's 
"cleanest-burning fossil fuel." In the words of Rich Colemanformer BC Minister of Energy and Mines, exporting BC LNG could "significantly lower global greenhouse gas production by replacing coal-fired power plants and oil-based transportation fuels with a much cleaner alternative" (BC Ministry of Energy Mines, 2012, p. 1), which would allow the province to become a global leader in building a low carbon economy.

Despite aggressive propaganda efforts like Coleman's, the branding of natural gas as a "bridge" or "transition" fuel has been widely criticized within scholarly discussions. Such critiques tend to focus on the bridge fuel concept's inherent ambiguity and its advocacy for a slow phase out of hydrocarbon in the global energy system. Focusing on the case of BC LNG, Stephenson et al. (2012) reviewed existing empirical findings on the climate impacts of shale gas and reached the conclusion that it is highly problematic to consider shale gas as clean energy since factors impacting its lifecycle emissions are "poorly characterized and remain contested in the academic literature" (p. 452). Likewise, a recent report from Oil Change International (Stockman et al., 2019) argued that "the myth of gas as a 'bridge' to a stable climate does not stand up to scrutiny [...] [since] the greenhouse gas (GHG) emissions just from burning the gas itself are enough to overshoot climate goals" (p. 18), not mentioning issues such as methane leakage and the difficulty of closing down newly built gas infrastructure.

The problematic aspects of bridge fuel identified by previous research is truly alarming, yet media coverage often undermines such warnings. As recent studies such as Bomberg (2017) and Delborne et al. (2020) have found, arguments emphasizing shale gas' potential contributions to the transition to a low-carbon future have played a prominent role in mobilizing popular support for shale gas development. Little research, however, has offered detailed analysis of media debates over bridge fuel in countries where the stakes of energy politics are high. In light of this notable gap in previous literature, this study explores how Canadian media have discussed the role of natural gas in climate change mitigation from 2016 to 2019. It mainly focuses on the issue of knowledge mobilization, namely how fossil fuel proponents and opponents-by offering competing interpretations of the bridge fuel metaphor-communicate contradictory frames concerning the climate impacts of natural gas to the general public.

Below, I begin the inquiry by briefly discussing capitalism's dependence on fossil fuels, which highlights the importance of studying public communications surrounding historical and current energy transitions. This is followed by a brief overview of the bridge fuel controversy as well as metaphor research in environmental communication. Next, I present the data, methods, and results of the empirical analysis, with an explicit focus on different stakeholders' competing interpretations of bridge fuel found in media discussions. Finally, I conclude by assessing the analysis' findings and calling for more knowledge mobilization efforts to improve public understanding of shale gas.

\section{HISTORICAL ENERGY TRANSITIONS AND THE FORTHCOMING "GOLDEN AGE OF GAS"}

Considering that the ongoing shale gas boom is part of capitalism's systematic pursuit of "extreme carbon"unconventional hydrocarbons trapped in geological formations with poor permeability and porosity, it is crucial to conduct a brief historical review of the symbiotic relationship between fossil fuels and capitalism, thereby situating energy communication research in broader economic, social, and political contexts. According to energy humanities (see Szeman and Boyer, 2017; Szeman et al., 2017), fossil fuels have played a determinant role in the "accumulation by dispossession" (Harvey, 2011) process of capitalism since its infancy. In line with this argument, an exploration of the interconnection between fossil fuels and capitalism ought to start with what made coal the dominant energy source for the First Industrial Revolution. Conventional explanations for this historical process are known as the Ricardian-Malthusian paradigm (Wilkinson, 1973; Wrigley, 2010), which considers energy transition as an outcome of the interactions between the properties of different energy sources and socio-technical conditions. This paradigm thus proposes that an energy transition moves beyond the niche phase somewhat naturally when the advantages of an energy source become potent under certain social contexts. In the case of steam engine vs. water wheel, the former won because of its wide availability. Throughout the second half of the eighteenth century, the combination of productivity boost and population growth substantially increased Britain's energy demand, but during this period the country gradually ran out of streams suitable for running water wheels. In this context, coal-based steam power stood out for its independence from water sources and eventually enabled Britain to switch its energy base to coal.

Compared with the Ricardian-Malthusian paradigm, energy humanities scholarship attends to the socio-political and ideological dimensions of energy-society relations. Malm (2013), for instance, provides a different explanation for the rise of coal from the perspective of capital-labor relationship. His analysis of the swift expansion of steam engines during the first half of the nineteenth century sheds light on two parallel processes brought by steam power's appearance in the British cotton industry: the emergence of the factory system and the increasing mechanization of the production flow within it. Steam engines outpaced water wheels-albeit the latter being abundant, equally powerful, and generally cheaper-because the former created conditions for more efficient exploitation of surplus value. Back then, many streams were in remote areas which lacked skilled and disciplined labor, whereas steam engines could be used in populous towns or cities where large concentrations of workers enabled the possibility of lower wages due to competition for employment. Not constrained by the flow of water, capitalism became mobile, with "the freedom to seek out the populous towns, where laborers are easily procured" (Malm, 2013, p. 40).

Whilst the growing coal sector in Northern Europe offered capitalists greater power over labor, it also enabled new forms 
of mass politics, which political theorist Mitchell (2009) defines as "carbon democracy." The energy networks mining and transporting coal assembled large numbers of workers at their main junctions (e.g., coal mines and railway stations). Given the importance of these junctions to capitalism, they became notable "choke points" that provided energy workers with a new kind of political power to make collective demands. Around the dawn of the twentieth century, coal miners led labor activism and political mobilization across major industrial countries (Podobnik, 2006).

From a communication perspective, the above review of Malm (2013) and Mitchell (2009) highlights how mainstream opinions following the Ricardian-Malthusian paradigm have concealed the political and ideological struggles underlying the rise of coal. A similar historical process occurred during the era of post-WWII economic boom (1948-1973) when the Keynesian-Fordist system strengthened the centrality of oil to capitalism. Abundant, accessible, and affordable oil from the Middle East played essential role in the era's unprecedented economic recovery and expansion (Mitchell, 2009; Huber, 2013; Urry, 2013). In North America, the post-war economic boom stimulated private car ownership, which subsequently formed the ideological foundation of the "American way of life." The prevalence of car-dependent lifestyle allows the mass dispersal of the urban population throughout a sprawling metropolis. Associated with this process of suburbanization is a less cohesive, fragmentary social structure symbolized by single-family houses that naturalize high energy consumption.

Ideologically, the car-dependent lifestyle encourages an entrepreneurial attitude, key to which is the idea that "life is structured by a social field wherein wealth and material goods justifiably flow into privatized hands that work hard to achieve a particular material standard of life" (Huber, 2013, p. xiv). With driving constantly mediating the fragmentary nature of suburban life, it offers deeply felt visions of satisfaction, freedom, and individualism and makes the public increasingly view both physical and social spaces as vast, open territories to be conquered by individual choices. Hence, the post-WWII period could be viewed as neoliberalism's incubation period wherein a popular resentment of government, taxes, and Keynesianism gradually accumulated.

This resentment eventually erupted when a series of structural crises seriously disrupted petro-based American society during the 1971-1982 economic stagnation. This "global slump" period (McNally, 2011) witnessed the car-dependent lifestyle's addiction to oil being justified as one of the basic needs of daily lives in North America, which have functioned as an ideological blockade against renewable energy since then. Although over the following decades capitalism has managed to restore profitability through the "flexible accumulation" regime under neoliberalism, it is unable to resolve the contradiction of a social reproduction model ultimately built on non-renewable hydrocarbon reserves (Harvey, 2011; McNally, 2011). Today, as Urry (2013) points out, we have entered a peak moment of carbon-intensive capital accumulation. Confronted with the increasing difficulty and cost of conventional oil and gas extraction, global capitalism is subject to an imminent, permanent decline in energy supply. It is in this predicament that global capitalism begins to aggressively pursue unconventional fossil fuels via new extraction technologies such as fracking and offshore drilling.

As shown in the above historical review, an energy transition amplifies the social visibility of extractivism and complex interplays between energy and power. Although the extent to which unconventional fossil fuels can fulfill future energy demand remains uncertain, the shale gas boom across North America has captured the imagination of government and industry stakeholders. Emerging along this trend is the frequent appearance of metaphorical expressions on shale gas' economic and environmental impacts, such as the prevailing public discourse celebrating the forthcoming "golden age of gas" as well as the potential of shale gas as a bridge fuel for decarbonizing the global economy. Accordingly, an analysis of the ideological tension underlying metaphorical expressions like bridge fuel would offer new insights into capitalism's ongoing effects of securing its ever-growing energy demand. The next section further reviews recent scholarly discussions on the relationship between shale gas and carbon emissions reduction.

\section{NATURAL GAS AS A BRIDGE FUEL: THE CONTROVERSY}

A number of recent studies have assessed the implications of expanding unconventional gas development on the progress of decarbonization in different national contexts. Collectively, these studies have recognized several factors constraining the potential environmental benefits of increasing the share of gas in world energy consumption. Healey and Jaccard's (2016) analysis of the U.S. context found that without stringent carbon pricing policies, abundant and low-cost gas does not discernibly reduce U.S. annual GHG emissions. Their analysis highlights three key factors influencing the viability of gas as a bridge fuel, namely gas plant efficiency, methane leakage, and potential delays of near-zero-emission technologies (Hausfather, 2015; Zhang et al., 2016).

Focusing on the United Kingdom's electricity sector, Wilson and Staffell (2018) argued that whether gas could effectively lower GHG emissions from electricity production hinges up both infrastructure basis and political will. Specifically, the switch from coal to gas brings near-term carbon reduction only when the process mainly utilizes existing infrastructure, instead of incentivizing building new gas projects. A high price also needs to be placed on GHG emissions to encourage a quicker adoption of renewable energy sources. Without both conditions, the reliance on gas would eventually become irreconcilable with decarbonization targets.

At the global level, Levi's (2013) modeling of multiple climate stabilization scenarios shows that "in the context of the most ambitious stabilization objectives ( $450 \mathrm{ppm} \mathrm{CO}_{2}$ ), and absent carbon capture and sequestration, a natural gas bridge is of limited direct emissions-reducing value, since that bridge must be short" (p. 609). If energy policymaking prioritizes long-term climate impacts, then the climate benefits of replacing coal with shale gas is quite limited. 
Hence, although natural gas is less GHG intensive per unit energy than coal and crude oil, significantly increasing its share in electrical power generation and transportation may still hamper climate mitigation's long-term goals. This challenge is even recognized by experts who praise the potential of gas as an important complementary transition fuel. For instance, Safari et al. (2019) compared possible energy structure changes of four countries (India, Iran, Norway, and UK) and reached the conclusion that realizing the environmental benefits of gasfueled solutions encounter "challenges from the social, technical, economic, geographical, and political points of view" (p. 1,075).

Furthermore, the worldwide prevalence of horizontal drilling and hydraulic fracturing (hereafter as "fracking") in the gas industry requires us to question what hidden costs are embedded in the "dash for gas" proposed by Safari et al. (2019) and scholars alike. Papers assessing the environmental impacts of unconventional gas extraction have revealed the danger of equating gas produced from shale formations with conventional natural gas. In their landmark study of the GHG footprint of fracking, Howarth et al. $(2011,2012)$ found that methane leakage from this unconventional production method is so severe that "compared to coal, the footprint of shale gas is at least $20 \%$ greater and perhaps more than twice as great on the 20-years horizon" (2011, p. 679). The idea that shale gas is dirtier than coal in terms of comprehensive GHG impacts has been further evaluated in numerous follow-up studies, including-but not limited toBrandt et al. (2014), Howarth (2014), Jackson et al. (2014), Macey et al. (2014), Newell and Raimi (2014), Sanchez II and Mays (2015), and Russo and Carpenter (2019). Most evidence suggest that designating natural gas as a "clean fossil fuel" neglects the growing share of shale gas in the global gas market and presents an inappropriate simplification of fracking's significant threats to public health and the environment. Recently, Hmiel et al. (2020) conducted a study on how much methane in today's atmosphere comes from natural geologic sources by analyzing pre-industrial methane trapped in the Greenland ice sheet. The study's findings indicate that anthropogenic fossil $\mathrm{CH}_{4}$ emissions have been underestimated by $25-40 \%$ in recent estimates, which reiterates shale gas' alarming GHG impacts and the problematic framing of it as a bridge to sustainability.

Despite scholars' serious concern about the oversimplification of the challenges human beings face in energy transition by the gas industry, their voices are largely overlooked during public deliberations about gas infrastructure expansion. In their review of how British Columbia engaged with the bridge fuel characterization, for instance, Stephenson et al. (2012) found a series of misrepresentations about the climate impacts of shale gas production. Of particular relevance to the current study is their observation that huge gaps exist between the available evidence on lifecycle emissions of shale gas and LNG and official claims celebrating BC LNG's potential as a valid "climate solution.” BC LNG advocates' deliberate discursive manipulation of bridge fuel, according to Stephenson et al. (2012), makes the concept equivalent to greenwashing.

In line with this critique, McGlade et al. (2018) assessed several possible scenarios involving shale gas as a bridge to decarbonize the United Kingdom's energy system, and their analysis suggested that replacing coal-fired power plants with new gas-fired ones is neither cost-effective nor compatible with the country's ambitious climate targets. Accordingly, it is particularly problematic to promote the bridge fuel concept while ignoring the development of renewables. Disappointed by the dominance of bridge fuel in public discourse, environmental NGOs like Oil Change International (Stockman et al., 2019) have gone further by calling for debunking the bridge fuel myth and taking radical measures to phase out all fossil fuels as quickly as possible.

\section{METAPHORS IN ENERGY COMMUNICATION}

While the above energy policy studies reveal the contentious aspects of bridge fuel for policy debates, it is energy communication scholarship that sheds light upon the important roles journalists and news coverage play in mediating public understanding of shale gas. Much of the scholarship on this research topic has focused on factors influencing public perceptions of fracking. Matthews and Hansen's (2018) review of recent research on media coverage of fracking found that in both Europe and North America, news reports and opinion pieces tend to present fracking as producing either economic benefits or environmental risks. In recent years, media organizations' differences in ideological stances and sociopolitical backgrounds, combined with stakeholders' conflicting interpretations of the notion "threat," have led to intensifying polarization between the two sides. Specifically, while fracking opponents put emphasis on fracking's environmental threats, proponents rebut by addressing threats related to energy cost and security.

The complexity of fracking debates has also been highlighted in other studies (e.g., Dodge and Lee, 2017; Metze, 2017; Olive and Delshad, 2017; Buttny, 2019). Less scholarship, however, has explicitly analyzed how media coverage engages with the bridge fuel concept. When tracing discursive dynamics in U.K. fracking debates, Bomberg (2017) noted that bridge fuel functioned as a key frame supporting the pro-fracking coalition's "opportunity" storyline, yet her analysis did not elaborate the frame's discursive details, which the current study aims to examine.

The dearth of research on media discussions of bridge fuel is concerning, given how metaphors shape public understandings of human-natural relationship. As Lakoff and Johnson (1980) emphasized in their landmark work on "metaphors we live by," there is a homology between the linguistic system and the conceptual system: "the way we think, what we experience, and what we do every day is very much a matter of metaphor" (p. 3). Accordingly, the analysis of metaphorical expressions in everyday language offers a pivotal tool for explicating the cognitive processes of human beings. In line with Lakoff and Johnson's view on the metaphorical nature of human thought processes, Larson (2011) argued that "the way we speak about the natural world is not a transparent window, because it reflects the culture in which we live and its priorities and values" ( $p$. ix). In other words, underpinning environmental notions like 
sustainability are systems of metaphorical concepts constructed by cultural and social values. To a degree then, the metaphors we adopt to describe environmental problems reflect our deeper ideological responses to the planetary climate crisis.

For example, Nerlich and Jaspal (2012) surveyed press articles related to geoengineering from the 1980's to 2010, and their results suggested that during the target period public conversations over geoengineering were bolstered by three conceptual master-metaphors: "the planet is a body," "the planet is a machine," and "the planet is a patient/addict." These metaphors collectively legitimized geoengineering as a last resort technology for preventing the catastrophic outcomes of climate change. Nerlich and Jaspal further argued that using the catastrophe frame may lead to demoralization and fatalism, thereby discouraging public participation in climate change solutions. In light of this argument, the current study is interested in whether bridge fuel related news articles have a similar effect on closing down debates about climate change mitigation.

As for metaphors concerning the growing prevalence of unconventional gas extraction, previous research has focused on how they shape the social representations of the fracking process. For instance, Jaspal and Nerlich's (2014) analysis of fracking in the U.K. press revealed pervasive rhetorical strategies in arguments about fracking's benefits and risks. Pro-fracking arguments metaphorically constructed fracking as providing the world with a "breathing space," which personified the world as a patience anxiously waiting for a "medical fix." By contrast, anti-fracking arguments considered fracking as "choking," which constituted a metaphorical counterpoint. The intense discursive struggles between pro- and anti-fracking metaphors manifest in the U.S. context as well. According to a comparative analysis by Cotton et al. (2019), the term "fracking" carries both positive and negative connotations in American public opinions. While supporters associate this term with metaphors like "boom," "bonanza," and "revolution," opponents use metaphors like "death," "gamble," and "insanity" to convey the unpredictability of fracking in relation to long-term environmental planning. These metaphors construct two contradictory metaphorical framings of fracking: "economic gain across temporal horizons" vs. "risk tolerance and decision-making." Depending on which frame has been adopted by a news report, the bridge fuel metaphor could be considered as belonging to either "revolution" or "gamble." Considering the dynamics between U.S. and Canadian public opinions, the discursive tension identified by Cotton et al. (2019) warrants further research into bridge fuel discourses found in Canadian media.

Compared with the above analyses of fracking related metaphors, (Delborne et al., 2020) presents an exception that solely focuses on the evolvement of the bridge fuel metaphor since the 1970's. Their historical analysis revealed two interesting findings. First, this metaphor was born during the oil embargo of the 1970's and it was initially associated with coal, which back then was viewed as an attractive, safe (in comparison to nuclear energy) option to reduce the U.S. economy's reliance on foreign oil. The idea of coal as a bridge fuel may sound surprising, but back then it was even accepted by leading environmental organizations like the Sierra Club. It was until the late 1980's and early 1990's when climate change entered public view that energy conglomerates began to associate the metaphor with natural gas and present it as the "least harmful solution." This change indicates the metaphor's symbolic flexibility. Second, bridge fuel could be understood as an umbrella metaphor consisting of different meanings, and these means are broadly structured around three characterizations of the term "bridge" (Delborne et al., 2020, p. 3): (1) destination (where does the bridge lead?), (2) length (how long will we travel on the bridge?), and (3) material composition (what qualities make the bridge more attractive than the departure zone?).

Building upon Delborne and his colleagues' findings, the current study attends to the Canadian context. Although on the surface Canada shares many similarities with the United States, there are notable factors that make Canadian shale gas discourses unique. First and foremost, energy policy debates in Canada are inevitably under the influence of the intensifying public contestation over Alberta bitumen, which has been a focal point of Canadian environmental communication scholarship over the past decade. Briefly speaking, previous research has revealed many manipulative tactics adopted by government and industry stakeholders to conceal bitumen's environmental impacts. For instance, several studies (Davidson and Gismondi, 2011; Remillard, 2011; Takach, 2013; McCurdy, 2018) have examined the visual representations of bitumen. A prevailing pattern identified by these studies is various visual materials' (photographic essays, presentations, advertisements, etc.) romanization of the relationship between nature and bitumen development, which tells the bitumen story as "the application of human ingenuity and scientific and technological expertise to release oil from the chemical bonds of its bitumen form; and corporate and government determination to overcome the physical and economic challenges of opening up the northern frontier to the new industry" (Davidson and Gismondi, 2011, p. 42).

As Canada's expanding shale gas production is exportoriented, relevant public debates are less concerned with energy security, which presents a contrast to the U.S. context (see Dodge and Lee, 2017; Buttny, 2019). In British Columbia, for instance, urban residents' overall hostile attitude toward extractivism forces shale gas advocates to reply more heavily upon the bridge fuel metaphor as the moral justification for rallying public support. With this being said, the metaphor's circulation in the Canadian media sphere is expected to encounter more resistance than in the United States since the Canadian public tends to demonstrate a greater appetite for aggressive climate policies (Lachapelle et al., 2012) and lower acceptance of unconventional fossil fuels (Brunner and Axsen, 2020). Taking these factors into account, the current analysis expects to advance our understanding of the complexity of bridge fuel discourses by teasing out their distinct dynamics in the Canadian media sphere.

\section{METHODOLOGY}

The current analysis is inspired by Delborne et al.'s (2020) historical analysis of policy debates over the bridge fuel metaphor 
in the United States. According to their analysis, the deployments of the metaphor found in news articles and policy documents inhabit two general categories: (1) original interpretations, which praises the capacity of shale gas to "facilitate better security, environmental, and economic outcomes" (p. 4), and (2) bridge distortions, which challenge key elements of the metaphor. In light of the close tie between Canadian and American gas sectors, I expect the metaphor's appearance in Canadian media to follow the patterns identified by Delborne et al. (2020). With this being said, it is equally interesting to explore how contextual factors such as public preference for progressive climate policies and Indigenous resistance in Canada would interact with the metaphor's inherent paradox - treating a fossil fuel as a solution to climate change. In consideration of such factors, the analysis is guided by the following research questions:

1. What discursive contexts invoke the mention of bridge fuel?

2. Is there a difference in the ways pro- and anti-fracking stakeholders deploy the bridge fuel metaphor in Canadian media publications?

As for data collection, I began to assemble a corpus of mainstream Canadian media publications via a query in Factiva, using the search string "bridge fuel OR transition fuel." As I found during the query, the designations "bridge fuel" and "transition fuel" have been used without significant semantic differences. Accordingly, the inclusion of "transition fuel" captured publications that discuss the role of shale gas in energy transition, but do not adopt the "bridge fuel" designation. The target period was set between January 2016 and December 2019 because I was interested in how the Canadian media sphere responded to the Paris Agreement drafted between November and December 2015. The initial search in Factiva resulted 95 articles. I manually checked each article to ensure its relevance to the current analysis. Then, considering Factiva may miss some small community newspapers, I conducted an identical query in ProQuest's Canadian Newsstream database. The final corpus includes a total of 99 articles, including 48 from general news outlets and 51 from trade presses. Although the index of Canadian media by Factiva and ProQuest is thorough and consistent, the corpus may not be comprehensive. It is inevitable that small publications such as independent media and NGO reports are not captured by the data collection process. Despite such lapses, the corpus likely captures most public texts mentioning bridge fuel that were easily accessible the Canadian public over the target period.

In light of the corpus' relatively small size, qualitative thematic analysis presents an appropriate choice for data analysis. Thematic analysis by its very nature is a widely used yet poorly refined approach (Nowell et al., 2017; Lawless and Chen, 2019). As Ayres (2012), in her overview of this method, notes, "thematic analysis is primarily a descriptive strategy that facilitates the search for patterns of experience within a qualitative data set" (p. 2). What distinguishes thematic analysis from other more formulaic methods is its flexibility: although we may describe thematic analysis in terms of coding, data management, theme refinement, and pattern identification, in practice these activities occur simultaneously along with a researcher's gradual familiarization of his/her project. Yet, such flexibility poses additional difficulty of achieving analytical depth and trustworthiness. According to qualitative method experts such as Holloway and Todres (2003), the credibility of thematic analysis projects is often hampered by inconsistency and a lack of coherence. In face of this challenge, Nowell et al. (2017) propose a step-by-step approach that refines thematic analysis into six phases (p. 4): (1) Familiarizing yourself with your data, (2) generating initial codes, (3) searching for themes, (4) reviewing themes, (5) defining and naming themes, and (6) producing the report.

Following the suggestions from Nowell et al. (2017), I first read each article to get an overall impression of the corpus and documented my thoughts about potential codes/themes. Notably, the term "bridge fuel" only appeared in the titles of two articles, which suggested that most authors of the corpus did not consider it as a controversial or newsworthy concept. I then coded the corpus to categorize each article's primary theme, as determined by its title and lead paragraph. This inductive step resulted in six mutually exclusive themes: climate change, energy infrastructure, fracking, industry updates, liquefied natural gas (LNG), and U.S. politics. The topic of shale gas and energy transition remains peripheral in most articles, except for articles under the climate change theme. Next, I coded each article's specific mention of either bridge fuel or transition fuel according to the analytical framework developed by Delborne et al. (2020). This step identified four interpretations of the bridge fuel metaphor in the corpus: transitional fuel, a short bridge, destination fuel, and burning bridge. The next section provides detailed explanation of each interpretation. 2 weeks after the initial coding, I reviewed the codes to ensure intra-coder consistency. The review led to revisions of $<5 \%$ of the codes.

\section{FINDINGS}

Figure 1 depicts the yearly distribution of the corpus. Articles mentioning either bridge fuel or transition fuel began at 28 pieces in 2016, dropped to 21 and 19 respectively in 2017 and 2018, and bounced back up to 31 in 2019. Bridge fuel references in a given year mapped closely to policy debates and developments around shale gas and fracking. Major news events contributing to the 2016 result included the Paris Agreement, British Columbia's LNG development, and the U.S. presidential election, during which fracking triggered heated exchanges between its proponents and opponents. Likewise, in 2019 the renewed media interest in bridge fuel was mainly driven by growing public pressure calling for stronger climate actions in both North America and Europe. But overall, bridge fuel references in Canadian media remained low during 2016-2019. By comparison, during the same period Canadian national newspapers the Globe and Mail and the National Post alone produced more than 300 articles on the BC LNG controversy (Chen, 2020). Canadian media's lack of attention to bridge fuel presents a surprising finding, considering the country's continuing efforts on expanding fracking activities in recent years (see Thomas et al., 2017). 


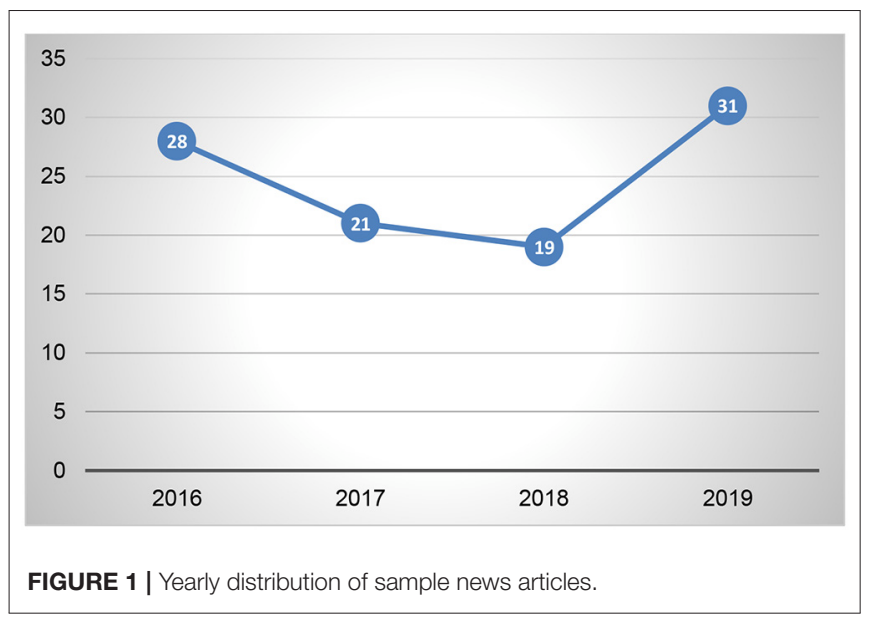

TABLE 1 | News themes in the corpus.

\begin{tabular}{lccccc}
\hline & $\mathbf{2 0 1 6}$ & $\mathbf{2 0 1 7}$ & $\mathbf{2 0 1 8}$ & $\mathbf{2 0 1 9}$ & Total \\
\hline Climate change & 8 & 3 & 4 & 3 & 18 \\
Energy infrastructure & 2 & 5 & 6 & 2 & 15 \\
Fracking & 5 & 4 & 5 & 5 & 19 \\
Industry updates & 0 & 4 & 2 & 20 & 26 \\
Liquefied natural gas & 8 & 1 & 0 & 0 & 9 \\
U.S. Politics & 5 & 4 & 2 & 1 & 12 \\
\hline
\end{tabular}

Regarding Research Question 1, Table 1 shows the themes of the collected articles. The frequency of different themes in a given year reveals several trends. To begin with, although climate change made a notable contribution to the 2016 result, related articles declined in subsequent years. Yet, this does not mean dwindling environmental concerns. Instead, there were recurring articles expressing growing public attention to fracking (i.e., articles under the "energy infrastructure" and "fracking" categories), which accounted for $34.34 \%$ of the corpus (34 out of 99). Articles under the "industry updates" theme had a significant increase in 2019. A closer look at these articles indicates that they were business reports based on press releases from energy companies that referred to bridge fuel to justify future growth potential. In a SNL Power Daily report on Xcel Energy (Horwath, 2019), for instance, the company spokesman Randay Fordice praised natural gas as an important bridge fuel to provide reliability for the company's plan of expanding its wind and solar generation capacity. Finally, the majority of articles under the themes "LNG" and "U.S. Politics" appeared in the years of 2016 and 2017 in correspondence to the peak period of public attention to both news events.

The above findings indicate that bridge fuel references are most likely to appear in news articles on energy or environmental issues. Among these articles, there is a discursive boundary dividing politicized and depoliticized bridge fuel discussions. Specifically, in news articles recognizing shale gas development as a political controversy, the bridge fuel metaphor tends to be challenged or critically assessed against other renewable options, as shown in the following excerpt from a roundtable discussion organized by the Toronto Star:

Steve Easterbrook [Director of University of Toronto's School of the Environment]: "People talk a lot about natural gas as a transition fuel because, per unit of energy, it has a lower carbon footprint than coal or oil. Some politicians would like to build more natural gas power plants and extract natural gas through fracking. My response is that if you want to build anything that is emitting carbon dioxide, you do not understand the scale of the problem. We cannot afford to build anymore infrastructure that depends on fossil fuels, whatsoever." (as cited in Ogilvie, 2019, para. 23).

Similarly, in a feature article published by SNL Daily Gas Report, renowned climate activist Bill McKibben criticized the bridge fuel metaphor for concealing the big methane and carbon damage done by shale gas:

\begin{abstract}
Is there a point at which methane emissions could be sufficiently controlled to make gas - as a coal or oil substitute-a preferable option? Not in the real world, especially because-and this is important-there's endless research showing that natural gas is now undercutting zero-carbon renewables with vicious power, so it's doing both big methane and big carbon damage. If gas is not a reasonable bridge fuel, how do we reliably and affordably address the large power demand in very concentrated urban areas without peaking fossil generation? (as cited in Smith, 2016, para. 9-11).
\end{abstract}

By comparison, news articles rejecting the public controversy around fracking simply treated shale gas as the energy source facilitating global capitalism's "business-as-usual" growth. Despite recognizing the imminent threat of climate change, these articles considered bridge fuel as the solution making climate change mitigation compatible with the world's current carbonintensive mode of social reproduction. They also insisted that the increasing usage of shale gas should retire coal and crude oil in a gradual manner. For example, in a SNL Energy Finance Daily interview, Julia Hamm-CEO of the Smart Electric Power Alliance (a Washington-based NGO made up by stakeholders from electric utilities and technology companies)-downplayed the urgency of energy transition:

\footnotetext{
Julia Hamm: "The fact is that we are in a transition and the transition takes time. It's not going to happen overnight. As we see more and more coal retirements, the equation will change. Certainly, we've seen this increase in natural gas, but a lot of people think about that as a bridge fuel to more renewables. I think it's just a question of timing on when we get to the point where the system is smart enough to be able to ensure the reliability of the system with a more distributed set of assets. But again, that can't happen overnight. It takes time and it needs to be balanced and done in a thoughtful and intentional way." (as cited in Hering, 2018, para. 8).
}

Hamm's reservation on renewables received additional support from pro-industry stakeholders in the government and media sectors who considered a slow phase-out of fossil fuels as a pragmatic approach to save the planet. Commenting on 
TABLE 2 | Bridge fuel references in the corpus.

\begin{tabular}{lccccc}
\hline & $\mathbf{2 0 1 6}$ & $\mathbf{2 0 1 7}$ & $\mathbf{2 0 1 8}$ & $\mathbf{2 0 1 9}$ & Total \\
\hline Transitional fuel & 17 & 11 & 13 & 15 & 56 \\
Destination fuel & 0 & 2 & 1 & 8 & 11 \\
Short bridge & 6 & 2 & 0 & 1 & 9 \\
Burning bridge & 5 & 6 & 5 & 7 & 23 \\
\hline
\end{tabular}

the climate implication of Trump's unexpected presidency, the Global and Mail columnist Konrad Yakabuski argued that:

The best hope for the planet lies not in massive investments in wind and solar power, which can never reliably supply more than a fraction of the energy a power-hungry planet needs. [... ] What's needed is an embrace of cleaner-than-coal natural gas as a transition fuel, an acceptance that the benefits of nuclear energy outweigh its risks, and a moonshot focus on technologies that can truly end our dependence on fossil fuels or capture the carbon their combustion emits (Yakabuski, 2017, p. 16-17).

Taken together, politicized and depoliticized opinions on bridge fuel contested with each other during the target period, and neither side achieved a clear upper hand.

To better understand the discursive dynamics surrounding bridge fuel, it is necessary to further explore its specific mentions in the corpus. Regarding Research Question 2, Table 2 shows the breakdown of four different interpretations of bridge fuel in the corpus. The results suggest that more than half of the corpus ( $N=56$ out of 99$)$ adhered to the "transitional fuel" interpretation, which, as defined by Delborne et al. (2020), proposes that renewable solutions are not yet competitive against fossil fuels and thus shale gas-as a clean fossil fuel-should serve as long as "innovation makes renewables sufficiently costeffective and scalable" (p. 4). Key to this interpretation is the notion of shale gas being an intermediate step of the global economy's decarbonization process.

Nevertheless, in the current corpus, the interpretation's deployment often failed to address two crucial questions: first, what sources will fulfill the increasing demand for natural gas; second, how long will the age of gas last. Such neglect made many bridge fuel discussions inherently ambiguous. For example, in the following Global and Mail article depicting Ontario's energy strategy after the Paris Agreement, natural gas was praised for being a greener alternative to coal, yet there was no mention regarding how to accelerate a transition from gas to renewables:

In the current environment, natural gas remains a vital and highly attractive transition fuel. It's cheap, abundantly available and much cleaner than coal or oil. That's why it's become the heating source of choice in Ontario [...]. The overarching principle should be to use the cleanest energy source available at the lowest possible cost. And natural gas offers the best bang for the buck when it comes to reducing emissions, particularly in industries and communities that use even dirtier fuels (McKenna, 2016, para. 9-10).
Many other articles in the corpus did not offer a formal definition or explanation of bridge fuel. In such articles, the metaphor was treated as a "common sense," which resulted in it being a peripheral contributor to their storylines, as shown in the following excerpt from a Global and Mail story on the LNG Canada project:

LNG Canada has received a relatively smooth ride compared with the Trans Mountain expansion (TMX) experience. The fundamental difference is the product. LNG is marketed as a lowcarbon, transition fuel that would help reduce global emissions. [By contrast] Mr. Horgan's government regards the diluted bitumen that would be shipped from Trans Mountain's line as a pending environmental disaster (Hunter and Jang, 2018, para. 3).

Perhaps because of the inherent ambiguity of "transitional fuel," three derived interpretations emerged from the corpus, which sought to direct public understanding of bridge fuel toward different visions of energy-society relationship. To begin with, articles adhering to "short bridge" accepted shale gas as a bridge to a lower carbon future but were cautious about the risk of new gas infrastructure's "lock-in" effect. Such articles thus framed shale gas as a short-term energy solution. Quoting a research report published by the Center for Sustainable Energy (CSE), a Business Wire article warned about the potential negative impacts of investing in gas-fired plants:

"With the exception of a few bumps and starts, the nation's history with natural gas use has been to consume as much as we can, as quickly as possible," said Steve Weissman, CSE's senior policy advisor and the paper's author. "As far as fossil fuels go, gas is perceived to be cheap, plentiful, versatile and cleaner than coal or oil. However, continued new investment in gas-fired plants thwarts efforts to stabilize greenhouse gasses." [as cited in New report calls for closer examination of natural gas (2016), para. 2].

Most "short bridge" articles were published in 2016, which probably resulted from public reactions to the Paris Agreement. These cautious voices, however, weakened in subsequent years. Judging from the trends shown in Table 2, the discursive space they occupied were taken by articles adhering to "destination fuel," which presented a conservative interpretation of bridge fuel. These articles proposed that given the disadvantages of renewables (esp. cost and reliability), shale gas should function as the basis of the global economy for at least the next century. According to Delborne et al. (2020), this proposal "positions natural gas as a bridge fuel as well as a destination itself" (p. 6 ), which denies climate change as a profound challenge to the political economy of global capitalism. Driven by the oil and gas sector's demand for policy incentives, the "destination fuel" articles had a notable increase in 2019. In a public address at the LDC Gas Forums, for instance, Catherine Reheis-Boydthe president of the Western States Petroleum Associationargued that:

The industry position in the future may depend on its ability to demonstrate its contributions to society and the environment. [...] This means launching a thoughtful, concerted effort to 
highlight the wage and other benefits the oil and gas industry provide to individual workers and the ways it contributes to broader communities in the form of tax revenue and economic activity. The sector should also avoid positioning natural gas as a "bridge fuel" to a renewable energy future and instead stress gas' potential long-term role complementing variable power sources like solar panels and wind turbines [as cited in DiChristopher (2019), para. 5].

In line with the "destination fuel" articles, articles adhering to "burning bridge" also marked a significant departure from the original interpretation. Yet, they considered bridge fuel itself as a greenwashing concept constructed by fossil fuel proponents. The "burning bridge" articles tended to express strong disbelief in the safety of fracking operations as well as the environmental benefits attributed to natural gas. As mentioned previously, a common concern shared among these articles (regardless of publication year) was methane leakage, which, in several "letters to the editor," motivated the authors' opposition to shale gas development. For example, a letter published at Kingston Whig Standard raised the alarm that:

\section{Methane is 84 times more potent as a climate pollutant than carbon dioxide and has a relatively short lifespan, so reducing methane emissions will have a quick and major impact on protecting our climate. It's time to invest in the clean energy economy. LNG/fracked gas is not a reasonable transition fuel (Cronin, 2017, para. 4-5).}

As discussed earlier, media coverage plays a crucial role in mediating public understanding of shale gas. The dominance of the "transitional fuel" interpretation in the corpus dismissed the controversial aspects of bridge fuel, which led to discursive enclosure for public deliberation on shale gas development. Although "short bridge" and "burning bridge" articles sought to offer alternative voices, it was challenging for them to open up the issue of bridge fuel for public debates, considering their combined frequency only accounted for $34.34 \%$ ( $N=34$ out of 99) of the corpus, which itself only accounted for a fraction of environmental and energy news stories during the 20162019 period.

\section{DISCUSSION AND CONCLUSION}

This paper unpacks how the bridge fuel metaphor evolved in the Canadian media sphere from 2016 to 2019. The empirical analysis suggests that references to the metaphor are most likely to appear in energy and environmental news stories. According to the current analysis, the majority of such references followed the original interpretation of bridge fuel, which describes a "concrete, intermediate step toward phasing out the worst energy sources (e.g., coal) while reducing overall carbon emissions" (Delborne et al., 2020, p. 4). Shale gas is proposed as the energy foundation of human society during this step because of its lower carbon footprint impacts than other fossil fuels. Meanwhile, there are three less common, yet noteworthy interpretations arising out of the data, which conflict with each other in terms of how they view the relationship between shale gas and greenhouse gas emissions reduction. Judging from the notable surge of "destination fuel" references in 2019, there has been coordinated industry efforts on defending the irreplaceability of fossil fuels in the global pollical economy. Equally alarming is the lack of meaningful discussion on the controversial aspects of bridge fuel in the corpus, which may have led to discursive enclosure of dissident voices. The current study provides empirical support for Stephenson et al.'s (2012) critique of bridge fuel being a greenwashing tactic: By suppressing dissident voices, media's advocacy for bridge fuel deceive the public with an illusionary world in which contemporary society's addiction to fossil fuels could be compatible with the imminent threats of climate change.

Although the data examined here ends in 2019, the bridge fuel discourse continues to expand in 2020 in North America and other continents. At time of writing (July 2020), a quick search of "bridge fuel" in Google News yielded 32 pages of results published over past year. A quick overview of results in the first few pages suggests that voices addressing "burning bridge" are on the rise. A DeSmog story (Cunningham, 2020) claimed that the global push for LNG has created a speculative "gas bubble." Likewise, an analysis (Vella, 2020) published by Power Technology urged for ambitious policymaking in preparation for the soon-to-come end for natural gas. Based on the plummeting costs of solar and wind farms, Clean Technica (Hanley, 2020) proclaimed that natural gas is no longer a bridge fuel to the future.

How to assess these examples in relation to the current analysis? A key commonality of these examples is that they are all published by specialty websites targeting environmentally conscious readers who are likely to be knowledgeable about the drawbacks of fracking and shale gas development. By contrast, in the domain occupied by trade presses and general news outletsthe focus of the current analysis, the bridge fuel metaphor remains largely uncontested.

Moreover, the analysis also reveals a concerning issue: of all the analyzed news articles, there was no discussion on Indigenous communities' opinions on shale gas development and energy transition; instead, these communities only appeared as protestors blocking pipelines and LNG terminals. This disengagement points to the bridge fuel discourse's inattention to Canadian contextual factors, which also reflects in the corpus' composition: many of the collected news articles focused on U.S. Politics or U.S. energy corporations.

From a theoretical point of view, this paper supports previous claims concerning the complexity of the bridge fuel metaphor and its mediation of public conversations over decarbonization (Delborne et al., 2020; McGlade et al. 2018; Stockman et al., 2019). Given that the Canadian media sphere tends to "depoliticize" the bridge fuel metaphor by treating it as a widely accepted rather than controversial notion, there is little hope that existing media discourse justifying further shale gas development would mobilize sufficient public support for strong climate policies. Public conversations over the role of natural gas in decarbonization can be a site for constructive exchanges between ideologically diverse stakeholders. However, it is important to ensure such exchanges are not dominated by the governmentindustry alliance, as suggested by participatory communication 
research (see Depoe et al., 2004). The gridlock in decarbonizing the global economy demands the search for creative solutions. To initiate this process, knowledge mobilization efforts need to not only raise public awareness of the politics underlying bridge fuel but also propose new metaphors for political mobilization, such as renewing the war metaphor in climate change action (Mangat and Dalby, 2018) and reframing shale gas as "roadblock" to decarbonization (Cotton et al., 2019).

Recently, we have witnessed the growing enthusiasm in the United States organized around the Green New Deal for a transition to carbon-free economy. In Canada, similar public conversations took place around the call for a "resilient recovery," which urges government and industry stakeholders to invest stimulus into the country's fast-growing clean energy and cleantech sectors during the post-COVID economic recovery. Although it remains unknown whether public outcries for fossil fuel divestment would accumulate sufficient momentum to challenge the dominance of natural gas in energy transition discussions, one thing is certain: radical imaginations are in need for building coalitions among multiple players to deliver the economic, social, and political revolutions required by effective climate change mitigation. The intermediate step proposed by bridge fuel proponents, unfortunately, presents a pragmatic yet conservative vision of human society's energy future, in which the energysociety nexus remains at the control of powerful fossil fuel corporations.

In conclusion, this study contributes to the energy communication scholarship by explicating recent discursive dynamics surrounding the bridge fuel metaphor in the Canadian context. Notably, the analysis highlights the difficulty to peg

\section{REFERENCES}

Ayres, L. (2012). "Thematic coding and analysis," in The Sage Encyclopedia of Qualitative Research Methods, ed. L. M. Given (Thousand Oaks, CA: Sage Publications), 868. Available online at: http://methods.sagepub.com (accessed July 16, 2020).

BC Ministry of Energy and Mines (2012). British Columbia's Natural Gas Strategy: Fuelling B.C.'S Economy for the Next Decade and Beyond. Available online at: https://vufind.llbc.leg.bc.ca/ (accessed July 16, 2020).

Bomberg, E. (2017). Shale we drill? Discourse dynamics in UK fracking debates. J. Environ. Policy Plan. 19, 72-88. doi: 10.1080/1523908X.2015.1053111

Brandt, A. R., Heath, G. A., Kort, E. A., O’Sullivan, F., Pétron, G., Jordaan, S. M., et al. (2014). Methane leaks from north american natural gas systems. Science 343, 733-735. doi: 10.1126/science. 1247045

Brunner, T., and Axsen, J. (2020). Oil sands, pipelines and fracking: citizen acceptance of unconventional fossil fuel development and infrastructure in Canada. Energy Res. Soc. Sci. 67:101511. doi: 10.1016/j.erss.2020.101511

Buttny, R. (2019). Debating hydrofracking: the discursive construction of risk. Front. Commun. 4:5. doi: 10.3389/fcomm.2019.00005

Chen, S. (2020). Debating resource-driven development: a comparative analysis of media coverage on the Pacific Northwest LNG project in British Columbia. Front. Commun. 5:66. doi: 10.3389/fcomm.2020.00066

Cotton, M., Barkemeyer, R., Renzi, B. G., and Napolitano, G. (2019). Fracking and metaphor: analyzing newspaper discourse in the USA, Australia and the United Kingdom. Ecol. Econ. 166:106426. doi: 10.1016/j.ecolecon.2019.1 06426 down one consistent way the bridge fuel metaphor functions due to its evolvement along with changing energy politics. It also reveals how the media texts have strategically downplayed controversial topics like Indigenous communities' complex views on resource extraction. Overall, such findings speak to the pressing need for assessing the bridge fuel metaphor's further impacts on energy policy making. In line with Delborne et al. (2020), I would like to end this article by calling for more scholarly attention to the bridge fuel metaphor's increasingly prominent role in silencing radical voices in the politics of climate change. Ultimately, this study shed light upon the importance of building a discursive space for countering the bridge fuel metaphor and promoting political engagement with climate change.

\section{DATA AVAILABILITY STATEMENT}

The raw data supporting the collisions of this study are available on request to the corresponding author.

\section{AUTHOR CONTRIBUTIONS}

SC conceived and designed the study, collected, coded and analyzed materials, and wrote the manuscript.

\section{FUNDING}

This research was funded by a Vanier CGS Doctoral Scholarship awarded by the Social Sciences and Humanities Research Council of Canada and a Start-up Research Fund awarded by Ryerson University.
Cronin, C. (2017). Methane Serious Threat. Kingston Whig Standard, A4. Available online at: http://global.factiva.com (accessed May 27, 2020).

Cunningham, N. (2020). Global push for LNG creates "gas bubble" that could bust. DeSmog. Available online at: https://www.desmogblog.com/ (accessed July 16, 2020).

Davidson, D. J., and Gismondi, M. (2011). Challenging Legitimacy at the Precipice of Energy Calamity. New York, NY: Springer. doi: 10.1007/978-1-4614-0287-9

Delborne, J. A., Hasala, D., Wigner, A., and Kinchy, A. (2020). Dueling metaphors, fueling futures: "Bridge fuel" visions of coal and natural gas in the united states. Energy Res. Soc. Sci. 61:101350. doi: 10.1016/j.erss.2019.101350

Depoe, S. P., Delicath, J. W., and Elsenbeer, M. A. (2004). Communication and Public Participation in Environmental Policymaking. Albany, NY: State University of New York Press.

DiChristopher, T. (2019). As Calif. Climate measures spread, gas industry mulls playbook to push back. SNL Power Daily. Available online at: http://global. factiva.com (accessed May 27, 2020).

Dodge, J., and Lee, J. (2017). Framing dynamics and political gridlock: the curious case of hydraulic fracturing in New York. J. Environ. Policy Plan. 19, 14-34. doi: 10.1080/1523908X.2015.1116378

Hanley, S. (2020). Natural Gas as a Bridge Fuel to the Future? Not Anymore. Clean Technica. Available online at: https://cleantechnica.com/ (accessed July 16, 2020).

Harvey, D. (2011). The Enigma of Capital and the Crises of Capitalism. New York, NY: Oxford University Press.

Hausfather, Z. (2015). Bounding the climate viability of natural gas as a bridge fuel to displace coal. Energy Policy 86, 286-294. doi: 10.1016/j.enpol.2015.07.012 
Healey, S., and Jaccard, M. (2016). Abundant low-cost natural gas and deep GHG emissions reductions for the united states. Energy Policy 98, 241-253. doi: 10.1016/j.enpol.2016.08.026

Hering, G. (2018). "The transition takes time:" smart grid efforts face power sector inertia. SNL Energy Finance Daily. Available online at: http://global.factiva.com (accessed May 27, 2020).

Hmiel, B., Petrenko, V. V., Dyonisius, M. N., Buizert, C., Smith, A. M., Place, P. F., et al. (2020). Preindustrial CH4 indicates greater anthropogenic fossil CH4 emissions. Nature 578, 409-412. doi: 10.1038/s41586-020-1991-8

Holloway, I., and Todres, L. (2003). The status of method: flexibility, consistency and coherence. Qual. Res. 3, 345-357. doi: 10.1177/1468794103033004

Horwath, J. (2019). Xcel energy's path to carbon-free power leans on natural gas. SNL Power Daily. Available online at: http://global.factiva.com (accessed May 27, 2020).

Howarth, R., Santoro, W., and Ingraffea, R. (2011). Methane and the greenhousegas footprint of natural gas from shale formations. Clim. Change 106, 679-690. doi: 10.1007/s10584-011-0061-5

Howarth, R., Santoro, W., and Ingraffea, R. (2012). Venting and leaking of methane from shale gas development: response to cathles et al. Clim. Change 113, 537-549. doi: 10.1007/s10584-012-0401-0

Howarth, R. W. (2014). A bridge to nowhere: methane emissions and the greenhouse gas footprint of natural gas. Energy Sci. Eng. 2, 47-60. doi: $10.1002 /$ ese 3.35

Huber, M. (2013). Lifeblood: Oil, Freedom, and the Forces of Capital. Minneapolis, MN: University of Minnesota Press. doi: 10.5749/minnesota/9780816677849.001.0001

Hunter, J., and Jang, B. (2018). The path for pipelines: how B.C. is embracing one, fighting another. The Globe and Mail (Breaking News). Available online at: http://global.factiva.com (accessed May 27, 2020).

Jackson, R. B., Vengosh, A., Carey, J. W., Davies, R. J., Darrah, T. H., O'Sullivan, F., et al. (2014). The environmental costs and benefits of fracking. Annu. Rev. Environ. Resourc. 39, 327-362. doi: 10.1146/annurev-environ-031113-144051

Jaspal, R., and Nerlich, B. (2014). Fracking in the UK press: threat dynamics in an unfolding debate. Public Understand. Sci. 23, 348-363. doi: $10.1177 / 0963662513498835$

Lachapelle, E., Borick, C. P., and Rabe, B. (2012). Public attitudes toward climate science and climate policy in federal systems: Canada and the United States compared. Rev. Policy Res. 29, 334-357. doi: 10.1111/j.1541-1338.2012.00563.x

Lakoff, G., and Johnson, M. (1980). Metaphors We Live By. Chicago, IL: University of Chicago Press.

Larson, B. (2011). Metaphors for Environmental Sustainability: Redefining Our Relationship with Nature. New Haven, CT: Yale University Press.

Lawless, B., and Chen, Y. (2019). Developing a method of critical thematic analysis for qualitative communication inquiry. Howard J. Commun. 30, 92-106. doi: $10.1080 / 10646175.2018 .1439423$

Levi, M. (2013). Climate consequences of natural gas as a bridge fuel. Clima. Change 118, 609-623. doi: 10.1007/s10584-012-0658-3

Macey, G. P., Breech, R., Chernaik, M., Cox, C., Larson, D., Thomas, D., et al. (2014). Air concentrations of volatile compounds near oil and gas production: a community-based exploratory study. Environ. Health 13:82. doi: 10.1186/1476-069X-13-82

Malm, A. (2013). The origins of fossil capital: from water to steam in the British cotton industry. Hist. Mater. 21, 15-68. doi: 10.1163/1569206X-12341279

Mangat, R., and Dalby, S. (2018). Climate and wartalk: metaphors, imagination, transformation. Elementa 6:58. doi: 10.1525/elementa.313

Matthews, J., and Hansen, A. (2018). Fracturing debate? a review of research on media coverage of "fracking". Front. Commun. 3:41. doi: $10.3389 /$ fcomm.2018.00041

McCurdy, P. (2018). From the natural to the manmade environment: the shifting advertising practices of Canada's oil sands industry. Can. J. Commun. 43, 33-52. doi: $10.22230 / \mathrm{cjc} .2018 \mathrm{v} 43 \mathrm{n} 1 \mathrm{a3} 315$

McGlade, C., Pye, S., Ekins, P., Bradshaw, M., and Watson, J. (2018). The future role of natural gas in the UK: a bridge to nowhere? Energy Policy 113, 454-465. doi: 10.1016/j.enpol.2017.11.022

McKenna, B. (2016). Ontario's energy strategy a moving target. The Globe and Mail (Breaking News). Available online at: http://global.factiva.com (accessed May 27, 2020).

McNally, D. (2011). Global Slump: The Economics and Politics of Crisis and Resistance. Winnipeg, SK: Fernwood Publishing.
Metze, T. (2017). Fracking the debate: frame shifts and boundary work in Dutch decision making on shale gas. J. Environ. Policy Plan. 19, 35-52. doi: 10.1080/1523908X.2014.941462

Mitchell, T. (2009). Carbon democracy. Econ. Soc. 38, 399-432. doi: $10.1080 / 03085140903020598$

Nerlich, B., and Jaspal, R. (2012). Metaphors we die by? Geoengineering, metaphors, and the argument from catastrophe. Metaphor. Symbol. 27, 131-147. doi: 10.1080/10926488.2012.665795

New report calls for closer examination of natural gas (2016). New report calls for closer examination of natural gas' role in a carbon-constrained future. Business Wire. Available online at: http://global.factiva.com (accessed May 27, 2020).

Newell, R. G., and Raimi, D. (2014). Implications of shale gas development for climate change. Environ. Sci. Technol. 48, 8360-8368. doi: 10.1021/es40 46154

Nowell, L. S., Norris, J. M., White, D. E., and Moules, N. J. (2017). Thematic analysis: striving to meet the trustworthiness criteria. Int. J. Qual. Methods 16, 1-13. doi: 10.1177/1609406917733847

Ogden, J., Jaffe, A. M., Scheitrum, D., McDonald, Z., and Miller, M. (2018). Natural gas as a bridge to hydrogen transportation fuel: insights from the literature. Energy Policy 115, 317-329. doi: 10.1016/j.enpol.2017.12.049

Ogilvie, M. (2019). The politics of climate change. The Toronto Star. A3. Available online at: http://global.factiva.com (accessed May 27, 2020).

Olive, A., and Delshad, A. B. (2017). Fracking and framing: a comparative analysis of media coverage of hydraulic fracturing in Canadian and U.S. newspapers. Environ. Commun. 11, 784-799. doi: 10.1080/17524032.2016.12 75734

Podobnik, B. (2006). Global Energy Shifts: Fostering Sustainability in a Turbulent Age. Philadelphia, PA: Temple University Press.

Remillard, C. (2011). Picturing environmental risk: the canadian oil sands and the national geographic. Int. Commun. Gazette 73, 127-143. doi: $10.1177 / 1748048510386745$

Russo, P. N., and Carpenter, D. O. (2019). Air emissions from natural gas facilities in new york state. Int. J. Environ. Res. Public Health 16:1591. doi: 10.3390/ijerph16091591

Safari, A., Das, N., Langhelle, O., Roy, J., and Assadi, M. (2019). Natural gas: a transition fuel for sustainable energy system transformation? Energy Sci. Eng. 7, 1075-1094. doi: 10.1002/ese3.380

Sanchez, II. N., and Mays, D. C. (2015). Effect of methane leakage on the greenhouse gas footprint of electricity generation. Clim. Change 133, 169-178. doi: 10.1007/s10584-015-1471-6

Smith, S. (2016). McKibben: Natural Gas "Doing Both Big Methane and Big Carbon Damage." SNL Daily Gas Report. Available online at: http://global.factiva.com (accessed May 27, 2020).

Stephenson, E., Doukas, A., and Shaw, K. (2012). Greenwashing gas: might a "transition fuel" label legitimize carbon-intensive natural gas development? Energy Policy 46, 452-459. doi: 10.1016/j.enpol.2012.04.010

Stockman, L., Trout, K., and Blumenthal, B. (2019). Burning the Gas "Bridge Fuel" Myth: Why Gas is Not Clean, Cheap, or Necessary. Oil Change International. Available online at: www.priceofoil.org (accessed June 30, 2020).

Szeman, I., and Boyer, D. (2017). Energy Humanities: An Anthology. Baltimore, MD: John Hopkins University Press.

Szeman, I., Wilson, S., and Carlson, A. (2017). Petrocultures: Oil, Politics, Culture. Montreal: McGill-Queen's University Press.

Takach, G. (2013). Selling nature in a resource-based economy: romantic/extractive gazes and alberta's bituminous sands. Environ. Commun. 7, 211-230. doi: 10.1080/17524032.2013.778208

The International Energy Agency (2011). Are We Entering a Golden Age of Gas? Available online at: https://www.iea.org/ (accessed June 6, 2020).

Thomas, M., Pidgeon, N., Evensen, D., Partridge, T., Hasell, A., Enders, C., et al. (2017). Public perceptions of hydraulic fracturing for shale gas and oil in the United States and Canada: public perceptions of hydraulic fracturing. Wiley Interdiscip. Rev. Clim. Change 8:e450. doi: 10.1002/wcc.450

Urry, J. (2013). Societies Beyond Oil: Oil Dregs and Social Futures. London, UK: Zed Books.

Vella, H. (2020). Bridge to Nowhere: Does Natural Gas Energy Have a Future? Power Technology. Available online at: https://www.power-technology.com/ (accessed July 16, 2020).

Wilkinson, R. G. (1973). Poverty and Progress: An Ecological Model of Economic Development. London, UK: Methuen Publishing. 
Wilson, I. A. G., and Staffell, I. (2018). Rapid fuel switching from coal to natural gas through effective carbon pricing. Nat. Energy 3, 365-372. doi: 10.1038/s41560-018-0109-0

Wrigley, E. A. (2010). Energy and the English Industrial Revolution, Cambridge, UK: Cambridge University Press. doi: 10.1017/CBO9780511779619

Yakabuski, K. (2017). Why Trump Won't Kill the Planet. The Globe and Mail (Breaking News). Available online at: http://global.factiva.com (accessed May 27, 2020).

Zhang, X., Myhrvold, N. P., Hausfather, Z., and Caldeira, K. (2016). Climate benefits of natural gas as a bridge fuel and potential delay of near-zero energy systems. Appl. Energy 167, 317-322. doi: 10.1016/j.apenergy.2015.10.016
Conflict of Interest: The author declares that the research was conducted in the absence of any commercial or financial relationships that could be construed as a potential conflict of interest.

Copyright (c) 2020 Chen. This is an open-access article distributed under the terms of the Creative Commons Attribution License (CC BY). The use, distribution or reproduction in other forums is permitted, provided the original author $(s)$ and the copyright owner(s) are credited and that the original publication in this journal is cited, in accordance with accepted academic practice. No use, distribution or reproduction is permitted which does not comply with these terms. 